\title{
A Kinetic Model to Predict the Compositions of Metal, Slag and Inclusions during Ladle Refining: Part2. Condition to Control the Inclusion Composition
}

\author{
Akifumi HARADA, ${ }^{1{ }^{1 *}}$ Nobuhiro MARUOKA, ${ }^{2)}$ Hiroyuki SHIBATA ${ }^{2)}$ and Shin-ya KITAMURA ${ }^{2)}$ \\ 1) Department of Metallurgy, Graduate School of Engineering, Tohoku University, 2-1-1 Katahira, Aoba-ku, Sendai, $980-8577$ \\ Japan. $\quad 2$ Institute of Multidisciplinary Research for Advanced Materials, Tohoku University, 2-1-1 Katahira, Aoba-ku, \\ Sendai, 980-8577 Japan.
}

(Received on April 7, 2013; accepted on July 16, 2013)

\begin{abstract}
A kinetic model to simulate the reactions in a ladle furnace was developed in the previous paper. The following parameters were considered in this model; (1) ratio of the entrapment of slag in the molten steel, (2) ratio of the floatation of the deoxidation products and inclusions originating from the slag, (3) ratio of the agglomeration of deoxidation products with inclusions originating from the slag and (4) ratio of the volume of the bulk zone to the total volume of molten steel and that of slag phase. These parameters were optimized using sensitivity calculation by comparison with operational results as the parameters affected the amount and composition of inclusions.

Then, the method to suppress the formation of $\mathrm{MgO} \cdot \mathrm{Al}_{2} \mathrm{O}_{3}$ spinel-type inclusion was discussed using the optimized parameters. The calculated results showed that the formation of $\mathrm{MgO} \cdot \mathrm{Al}_{2} \mathrm{O}_{3}$ spinel-type inclusion could be suppressed by optimizing the additional amount of $\mathrm{Al}$, initial content of $\mathrm{MgO}$ in the slag, and slag basicity in addition to the Ca treatment. The changes in the inclusions calculated using the kinetic model were in good agreement with those predicted by the phase stability diagram. The developed model was useful for optimizing the operation of a ladle furnace.
\end{abstract}

KEY WORDS: ladle metallurgy; kinetic simulation; inclusion; spinel; slag; Ca treatment.

\section{Introduction}

As the demand for high-quality steel continues to increase, the ladle refining process has become increasingly important in recent times to obtain molten steel with the suitable composition and cleanness. Precise control of the inclusion composition and the reduction of the sulfur content of steel are very important. However, the reactions in the ladle treatment of steel are complex because they occur simultaneously among the molten steel, added alloying elements, slag, and refractory; thus, the mechanisms of the changes in the inclusion composition have not yet been fully understood.

We previously reported a kinetic model that was developed to analyze the changes in the composition of inclusions during ladle refining. ${ }^{1)}$ The calculation results were in good agreement with the operational results reported by Graham et $a{ }^{2}{ }^{2)}$ In the model, in every time interval, a part of the slag is assumed to be entrapped in the metal at a constant ratio $(\alpha)$, a part of the deoxidation products is assumed to agglomerate with the inclusion originating from the slag at a constant ratio $(\gamma)$, and a part of the deoxidation products and a portion of the inclusion originating from the slag are

* Corresponding author: E-mail: a.harada@mail.tagen.tohoku.ac.jp DOI: http://dx.doi.org/10.2355/isijinternational.53.2118 assumed to float in the slag at a constant ratio $(\beta)$. In addition, the molten steel and slag phases are separated into interface and bulk zones; the zones in each phase are circulated at a constant rate assuming a ratio of the bulk zone volume to the total volume of each phase $\left(\mathrm{V}_{\mathrm{b}} / \mathrm{V}\right)$. These parameters and the ratio of the bulk zone in the steel and slag phase affect the calculation results, especially the changes in the amount and composition of inclusions. Thus, for the calculation, optimal values for these parameters are necessary. In this paper, the effects of these parameters on the calculation results are discussed and the procedure for their optimization is shown.

In addition, the effects of some factors on the change in the composition of the inclusions during ladle refining are discussed using the developed model. In particular, the factors that affect the formation of $\mathrm{MgO} \cdot \mathrm{Al}_{2} \mathrm{O}_{3}$ spinel-type inclusion are discussed because it is desirable to reduce this spinel which often becomes a defect origin due to its high melting temperature and low deformability. Therefore, the conditions under which the formation of spinel inclusion is inhibited are introduced using the developed model.

\section{Optimization of the Parameters Using Sensitivity Calculations}

As detailed in the previous report, ${ }^{1)}$ the following param- 
eters are considered in the developed model:

(1) Ratio of the entrapment of slag in the molten steel in every time interval to the total amount of slag $(\alpha ; \% / \mathrm{s})$; this causes an increase in the volume of inclusion originating from the slag phase.

(2) Ratio of the floatation of the deoxidation products or inclusions originating from the slag in every time interval to the total amount of deoxidation products or inclusions originating from the slag $(\gamma ; \% / \mathrm{s})$.

(3) Ratio of the agglomeration of deoxidation products with inclusions originating from the slag to the total amount of deoxidation product phase in every time interval $(\beta ; \% / \mathrm{s})$.

(4) Ratio of the volume of the bulk zone to the total volume of molten steel and that of slag phase $\left(\mathrm{V}_{\mathrm{b}} / \mathrm{V}\right)$.

Since these parameters affect the calculation results, especially the composition and amount of inclusions, optimization of the parameters using sensitivity calculations followed by comparison with operational results is necessary. In this section, examples of the sensitivity calculations on the basis of operational results reported by Graham et al. are shown. The basic calculation conditions, original composition of the steel and slag, and details of the model are explained in the previous paper. ${ }^{1)}$

\subsection{Influence of the Entrapment Ratio of Slag in the Molten Steel}

The ratio of entrapment of slag in the molten steel $(\alpha)$ was varied under standard values for the other parameters, as listed in Table 1. The changes in the total amount of inclusions are shown in Fig. 1; the black arrows in this and the following figures indicate the time of the addition of the alloying elements with the increase in Ar gas flow rate for $450 \mathrm{~s}$ while the white one represents the time to increase Ar gas flow rate for $300 \mathrm{~s}$ without the addition of the alloying elements. For each entrapment ratio value, the amount of total inclusion increases at the early stage because most of the inclusions in this period are formed as deoxidation products by the addition of aluminum. Subsequently, when $\alpha$ is $10^{-3} \% / \mathrm{s}$, the amount of total inclusion becomes almost constant: The amounts of total inclusion and total oxygen calculated by Eq. (1), are $\sim 250$ and $90 \mathrm{ppm}$, respectively, $3000 \mathrm{~s}$ after the start of treatment. On the other hand, the amount of total inclusion decreases when $\alpha$ is smaller than $10^{-4} \% / \mathrm{s}$ : The amounts of total inclusion and total oxygen at $3000 \mathrm{~s}$ are $\sim 38$ and $16 \mathrm{ppm}$, respectively, when $\alpha$ is $10^{-4} \% / \mathrm{s}$, and $\sim 16$ and 8 ppm, respectively, when $\alpha$ is smaller than $10^{-5} \% / \mathrm{s}$.

$$
[\mathrm{O}]_{\text {Total }}=[\mathrm{O}]_{\mathrm{sol}}+[\mathrm{O}]_{\mathrm{insol}}
$$

Table 1. Parameter changes for sensitivity calculation.

\begin{tabular}{|c|c|c|}
\hline & Parameters & Ratio \\
\hline (1) & $\begin{array}{l}\text { Entrapment of slag into } \\
\text { molten steel }(\alpha)\end{array}$ & $10^{-3}, 10^{-4}, 10^{-5}, 10^{-6}(\% / \mathrm{s})$ \\
\hline (2) & $\begin{array}{l}\text { Floatation of inclusion } \\
\text { into slag phase }(\beta)\end{array}$ & $1, \mathbf{0 . 1}, 0.01(\% / \mathrm{s})$ \\
\hline (3) & $\begin{array}{l}\text { Agglomeration of } \\
\text { inclusion }(\gamma)\end{array}$ & $1,0.1,0.01(\% / \mathrm{s})$ \\
\hline (4) & $\begin{array}{l}\text { Bulk zone in molten steel } \\
\text { and slag phase }\left(V_{b} / V\right)\end{array}$ & $0.9, \mathbf{0 . 8}, 0.7$ \\
\hline
\end{tabular}

※ Bold font: Standard value
In Eq. (1), $[\mathrm{O}]_{\text {sol }}$ and $[\mathrm{O}]_{\text {insol }}$ are the contents of dissolved oxygen and oxygen converted by the amount of inclusion and its composition, respectively. When $\alpha$ is smaller than $10^{-4} \% / \mathrm{s}$, the calculation results are not significantly influenced by $\alpha$, as only a small amount of slag is entrapped and the amount of total inclusion is determined by the amount of deoxidation product. Although empirical total oxygen contents are not available in the literature, the total oxygen content after ladle-furnace (LF) treatment is generally lower than $20 \mathrm{ppm}$. Therefore, $\alpha$ is considered to be less than $10^{-4} \% / \mathrm{s}$. Figure 2 shows the influence of $\alpha$ on the changes in the average composition of the total inclusion with time. ${ }^{1)}$ When $\alpha$ is $10^{-6} \% / \mathrm{s}$, the calculated change in the $\mathrm{Al}_{2} \mathrm{O}_{3}$ content is in good agreement with the operational results. The calculated changes of $\mathrm{MgO}$ and $\mathrm{CaO}$ also show a tendency to increase, which is similar to that of the operational results. Therefore, the optimal ratio of entrapment of slag is determined to be $10^{-6} \% / \mathrm{s}$.

\subsection{Change in the Floatation Ratio of Inclusion in the Slag Phase}

The ratio of floatation of inclusion $(\beta)$ was varied, as listed in Table 1. The changes in the total amount of inclusion are shown in Fig. 3. In every case, the amount of total inclusion initially increases and then decreases except when alloying materials are added. The amounts of total inclusion and total oxygen after $3000 \mathrm{~s}$ are $\sim 170$ and $78 \mathrm{ppm}$, respectively, when $\beta$ is $0.01 \% / \mathrm{s}$, and $\sim 13$ and $7 \mathrm{ppm}$, respectively, when $\beta$ is $0.1 \% / \mathrm{s}$. When $\beta$ is larger than $1 \% / \mathrm{s}$, these values decrease to less than 0.1 and $0.9 \mathrm{ppm}$, respectively. Therefore, the optimal ratio of floatation of inclusion is determined to be $0.1 \% / \mathrm{s}$.

\subsection{Change in Agglomeration of the Inclusion}

The ratio of agglomeration of the inclusions $(\gamma)$ was varied, as listed in Table 1. The changes in the amount of total inclusion are shown in Fig. 4. The value of $\gamma$ does not significantly affect the change in the amount of total inclusions because the change in the formation rate or floatation rate by agglomeration is not considered in this model. Figure 5 shows the changes in the average composition of the total inclusion with time. ${ }^{1)}$ When $\gamma$ is 1.0 and $0.1 \% / \mathrm{s}$, the calculated change for each element is in good agreement with the operational results. Although the difference between 1.0 and

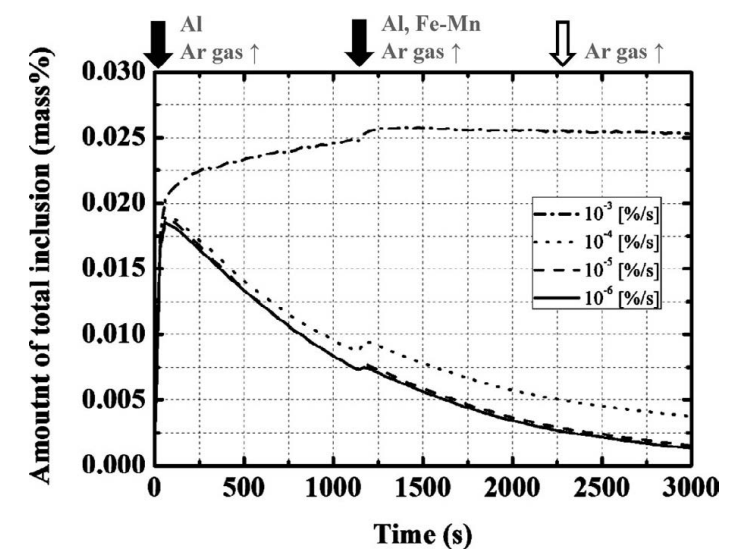

Fig. 1. Calculation results of the amount of total inclusion with the change in the ratio of the slag entrapment. 

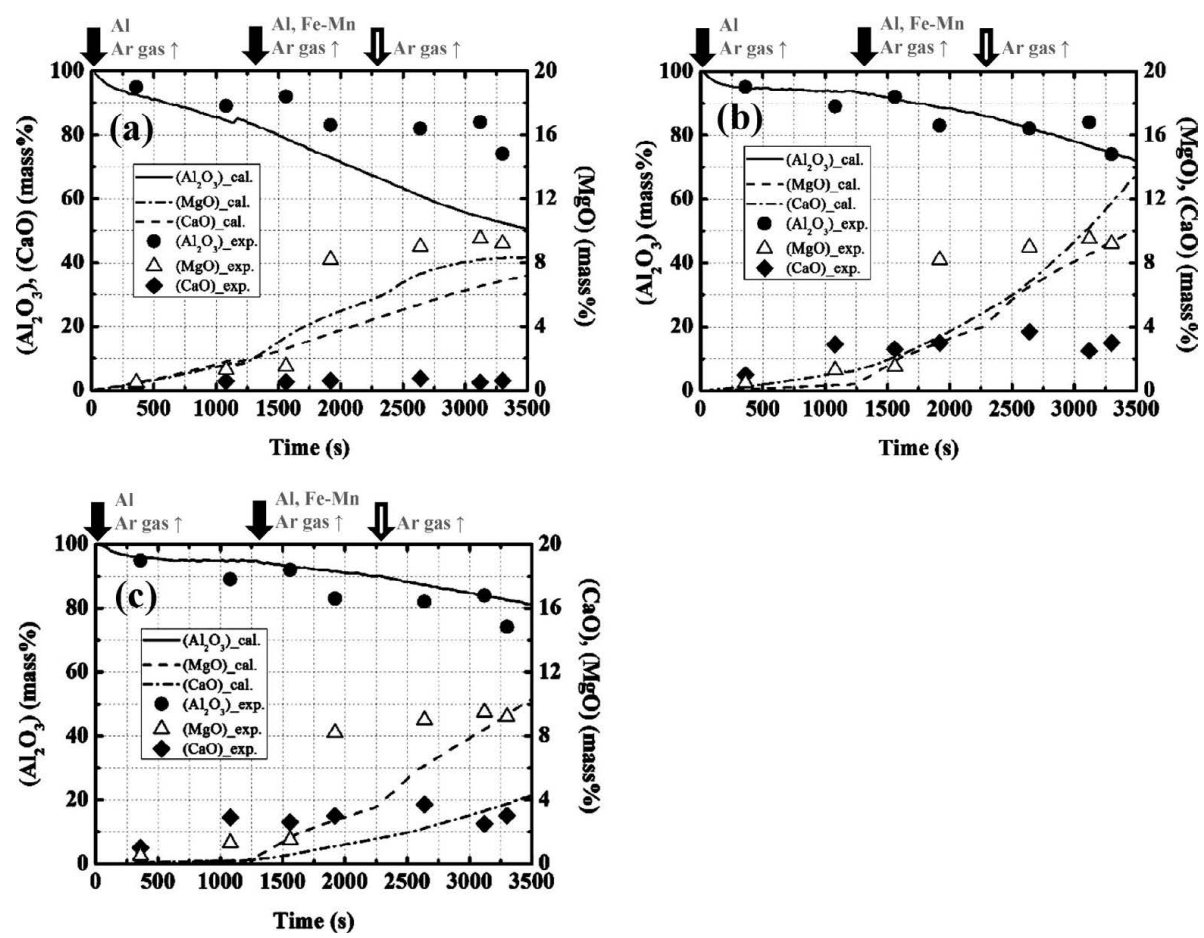

Fig. 2. Calculation results of the average concentration of each element in total inclusion at each ratio of the slag entrapment ((a) $10^{-4}[\% / \mathrm{s}]$, (b) $10^{-5}[\% / \mathrm{s}]$ and (c) $10^{-6}[\% / \mathrm{s}]$ ) in comparison with the operational results of the composition change with time.

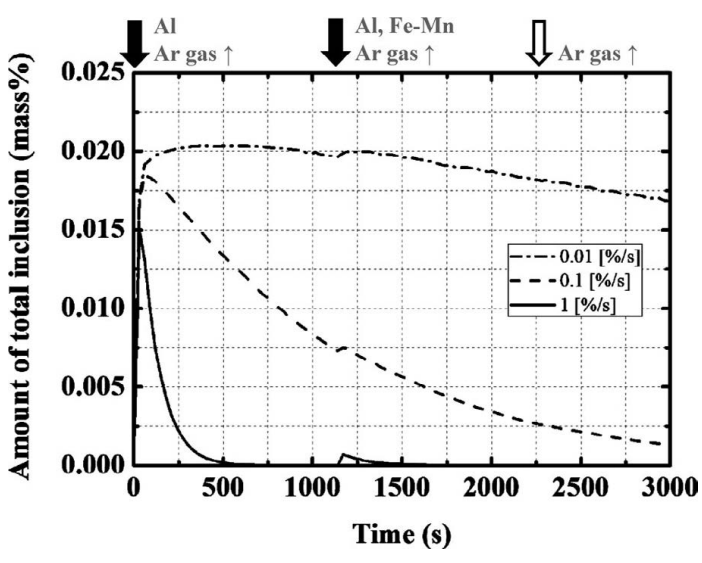

Fig. 3. Calculation results of the amount of total inclusion with the change in the ratio of floatation of the inclusion.

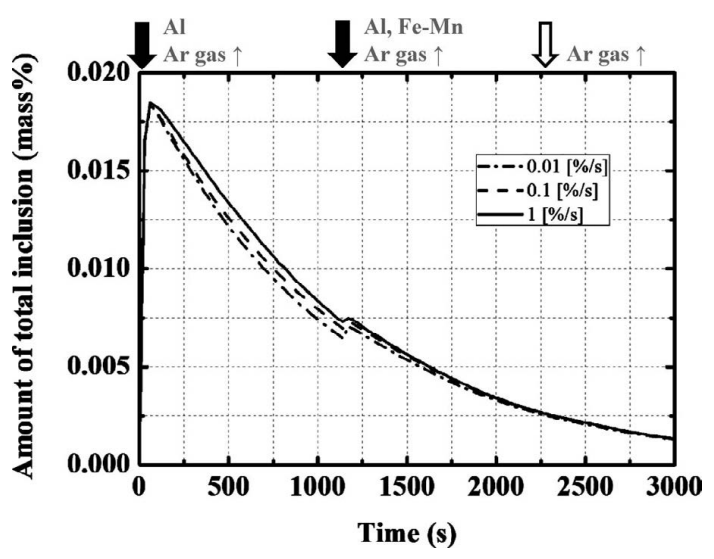

Fig. 4. Calculation results of the amount of total inclusion with the change in the ratio of agglomeration of the inclusion.

ume of molten steel or slag phase $\left(\mathrm{V}_{\mathrm{b}} / \mathrm{V}\right)$ was varied, as listed in Table 1. The changes in the total amount of inclusions with time are shown in Fig. 6. The influence of this parameter is small. In addition, the calculated changes in each element of the molten steel and slag were unaffected by this parameter.

Via these sensitivity calculations, the optimal parameters for the developed model were determined, as listed in Table 1. Using these optimal parameters, the industrial results of LF treatment were successfully simulated by this model, as shown in the previous paper. ${ }^{1)}$

\section{Discussion}

In this section, the effect of the addition of $\mathrm{Ca}$, additional amount of $\mathrm{Al}$, content of $\mathrm{MgO}$ in the slag, and slag basicity on spinel formation is discussed using the developed model 

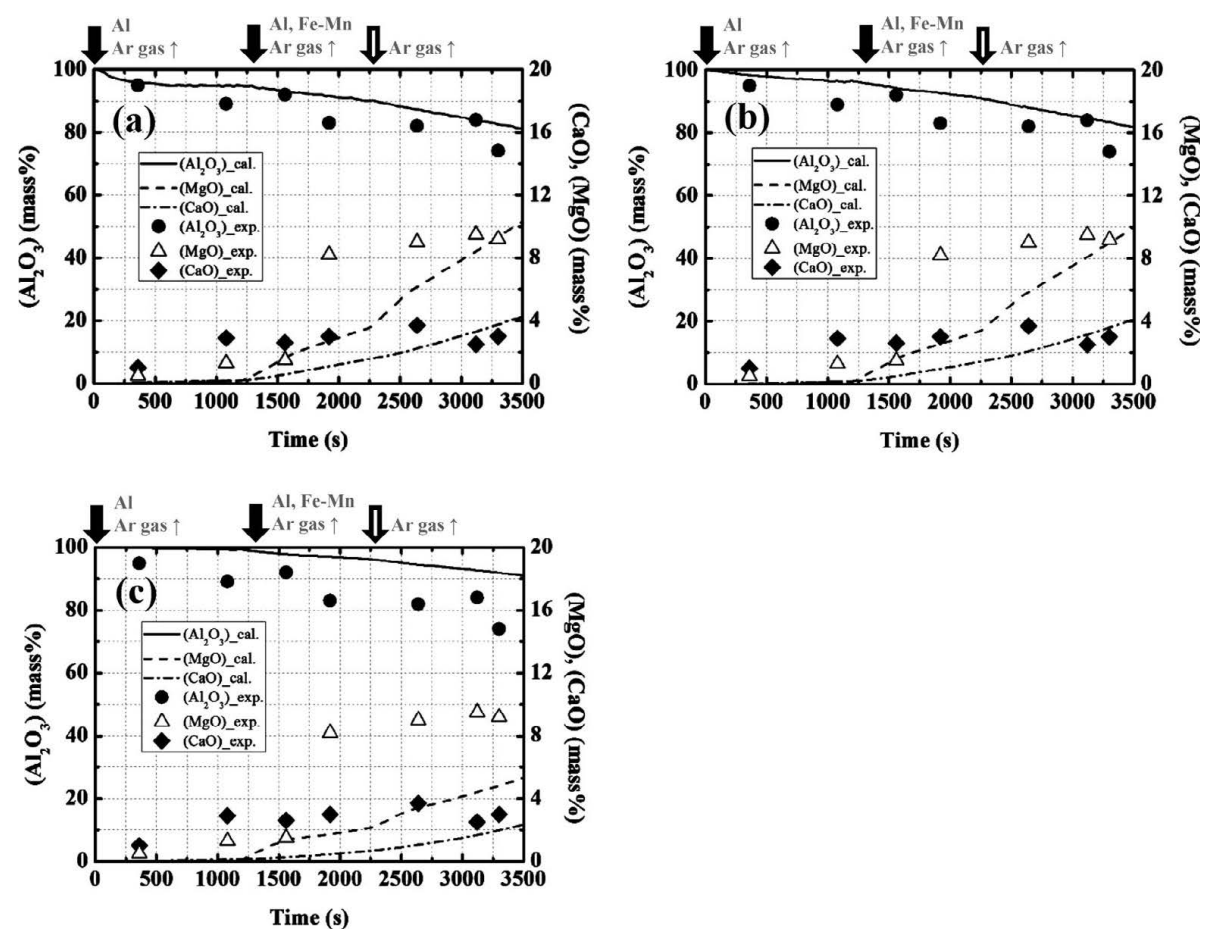

Fig. 5. Calculation results of the average concentration of each element in total inclusion at each ratio of agglomeration of the inclusion ((a) $1.0[\% / \mathrm{s}]$, (b) $0.1[\% / \mathrm{s}]$ and (c) $0.01[\% / \mathrm{s}]$ ) in comparison with the operational results of the composition change with time.

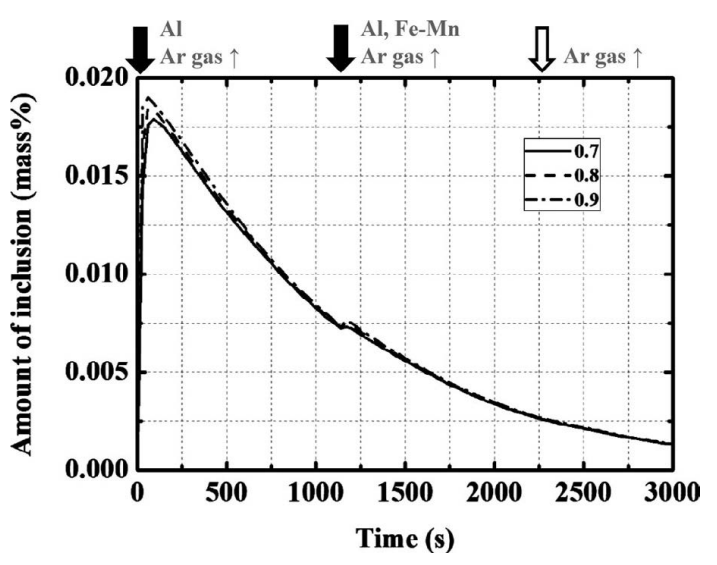

Fig. 6. Calculation results of the amount of total inclusion with the change in the ratio of bulk zone in the molten steel and slag.

and the empirical operation reported by Graham et al.

\subsection{Effect of Calcium Treatment on Composition Change in the Inclusions}

$\mathrm{Ca}$ treatment is a well-known technique for modifying inclusions. A model calculation was performed for the addition of $50 \mathrm{~g} / \mathrm{t}$ of calcium with $\mathrm{Al}$ and Fe-Mn at $1140 \mathrm{~s}$. Figure 7 shows the calculated changes in the $\mathrm{Mg}$ and $\mathrm{Ca}$ contents, and Fig. 8 shows the changes in the compositions of the inclusions originating from the slag. After $\mathrm{Ca}$ treatment, the content of $\mathrm{CaO}$ increases rapidly and the composition eventually becomes $\mathrm{CaO}-\mathrm{Al}_{2} \mathrm{O}_{3}$ containing a small amount of $\mathrm{MgO}$.

The calculated changes in the amounts of inclusions are shown in Fig. 9. The amount of inclusion originating from the slag increases due to entrapment of the slag and subsequently decreases due to floatation in the slag phase. Alumina-type

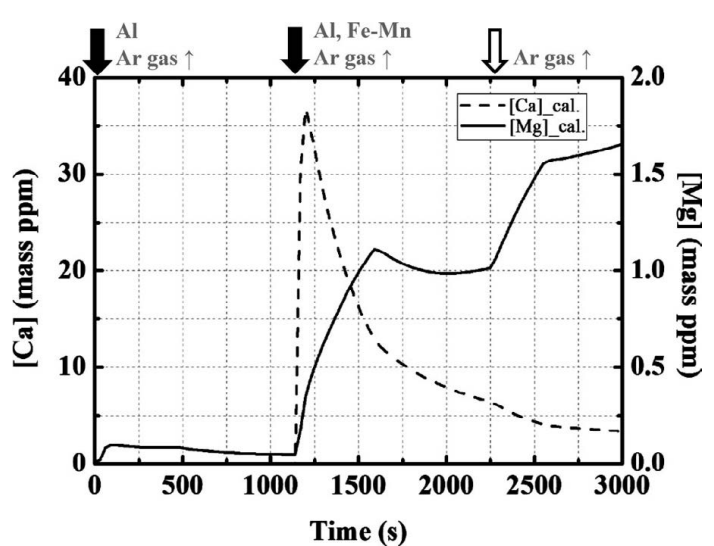

Fig. 7. Calculation results of the concentration of $\mathrm{Mg}$ and $\mathrm{Ca}$ in the molten steel.

inclusion forms as the deoxidation product by the addition of $\mathrm{Al}$ at $10 \mathrm{~s}$ (i.e., the first deoxidation), while $\mathrm{CaO}-\mathrm{Al}_{2} \mathrm{O}_{3}-$ type inclusion forms as the deoxidation product by the addition of $\mathrm{Ca}$ with $\mathrm{Fe}-\mathrm{Mn}$ and $\mathrm{Al}$ at 1140 s (i.e., the second deoxidation). However, spinel-type inclusion does not form. Soon after the first deoxidation, the amount of alumina-type inclusion decreases due to floatation. The ratio of each type of inclusion to the total mass of inclusions is shown in Fig. 10. In the early stages, the ratio of alumina-type deoxidation product is $\sim 70 \%$. Subsequently, the amount of alumina decreases due to agglomeration and floatation and most inclusions are changed to the inclusion originating from the slag. After the second deoxidation and $\mathrm{Ca}$ treatment, $\mathrm{CaO}-$ $\mathrm{Al}_{2} \mathrm{O}_{3}$-type inclusion forms. As the composition of the inclusion originating from the slag changes to $\mathrm{CaO}-\mathrm{Al}_{2} \mathrm{O}_{3}$ (Fig. 8), the composition of the inclusion is modified to $\mathrm{CaO}-\mathrm{Al}_{2} \mathrm{O}_{3}$, and the formation of spinel is suppressed by $\mathrm{Ca}$ 


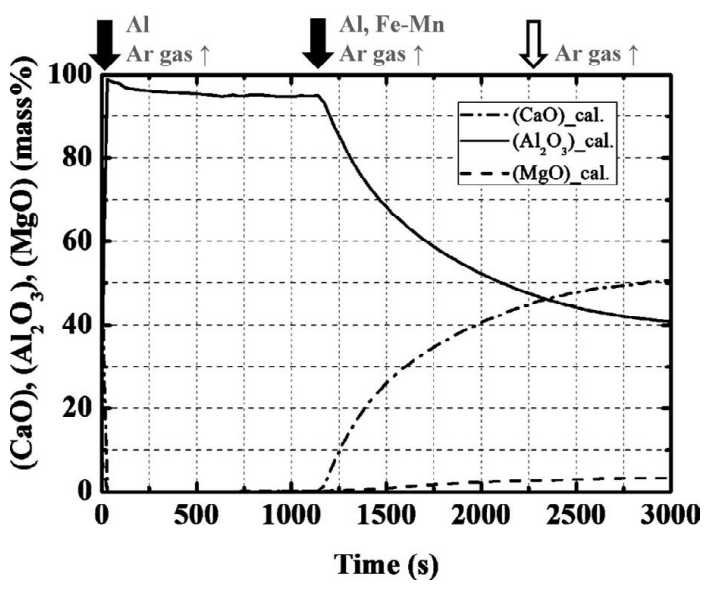

Fig. 8. Calculation results of the concentration of $\mathrm{CaO}, \mathrm{Al}_{2} \mathrm{O}_{3}$ and $\mathrm{MgO}$ in the inclusion originating from the slag.

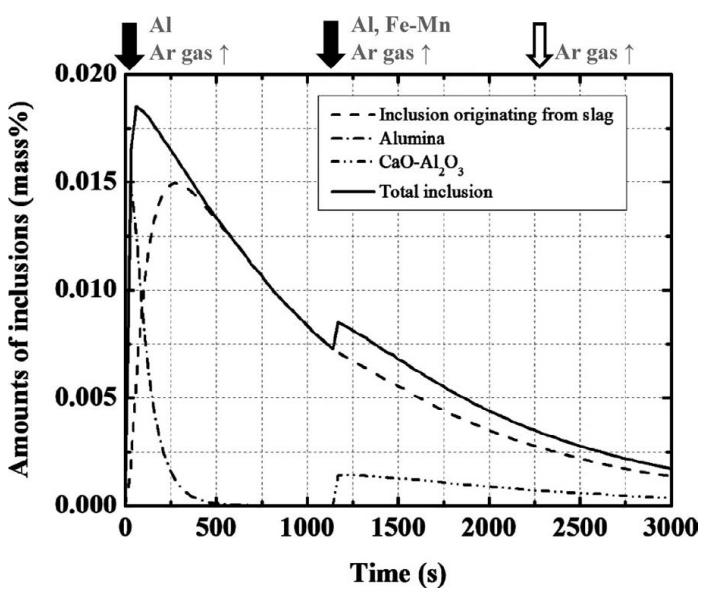

Fig. 9. Calculation results of the amount of total inclusion, inclusion originating from the slag, alumina and $\mathrm{CaO}-\mathrm{Al}_{2} \mathrm{O}_{3}$ type.

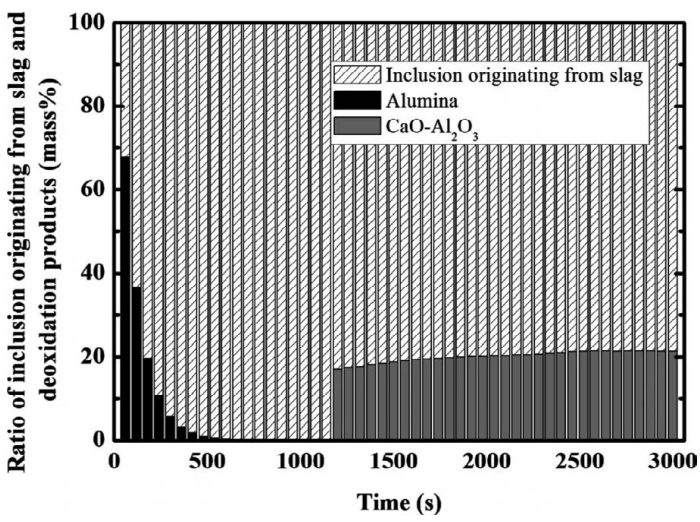

Fig. 10. Change in the ratio of the inclusion originated from the slag and the deoxidation products (alumina and $\mathrm{CaO}-$ $\mathrm{Al}_{2} \mathrm{O}_{3}$ type).

treatment.

\subsection{Effect of Additional Amount of Al on Composition Changes in the Inclusions}

Since aluminum is a strong deoxidation element, $\mathrm{MgO}$ in slag is reduced by $\mathrm{Al}$ in molten steel and $\mathrm{Mg}$ content in molten steel increases. The optimum Al content for suppressing the formation of spinel needs to be clarified. Therefore, cal-
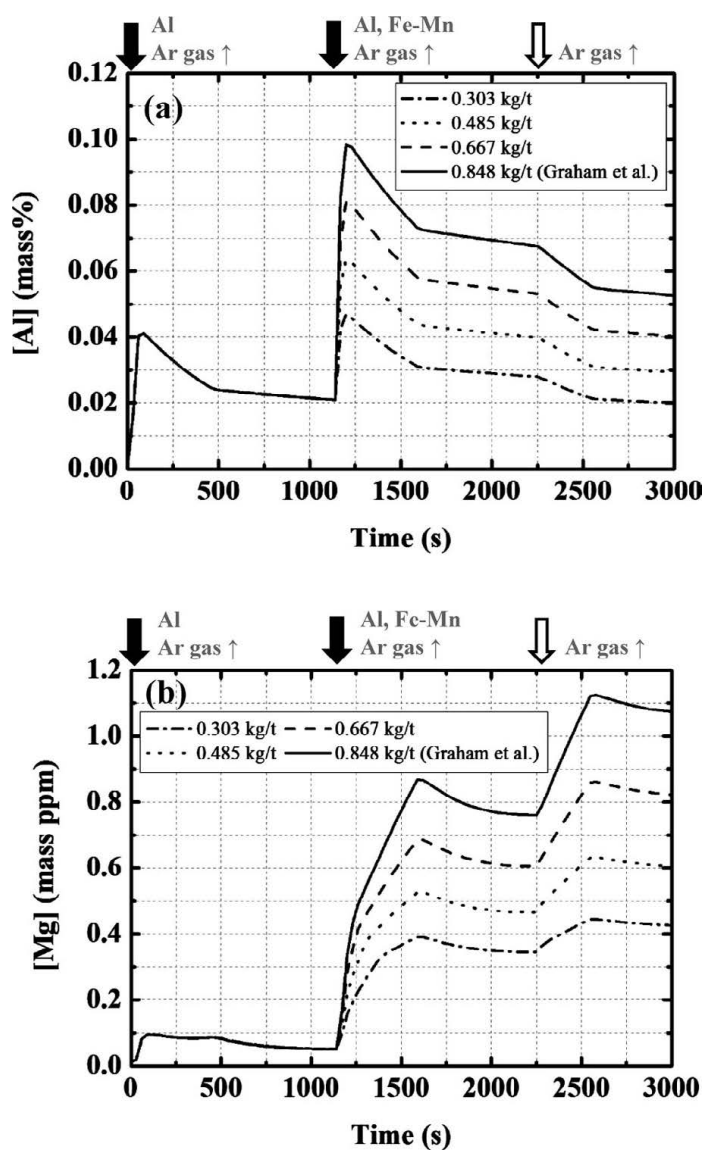

Fig. 11. Calculation results of the concentration of (a) Al and (b) $\mathrm{Mg}$ in the metal with the change in the additional amount of Al.

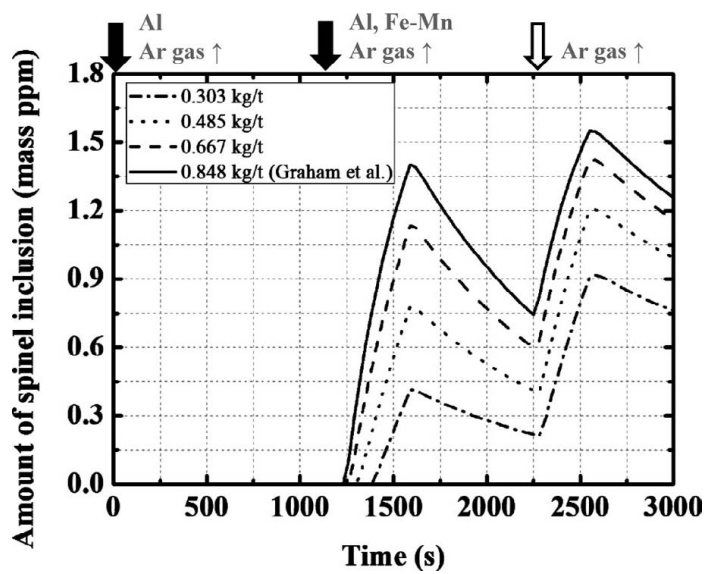

Fig. 12. Calculation results of the amount of spinel type inclusion with the change in the additional amount of Al.

culations with varying amounts of $\mathrm{Al}$ added (i.e., between 0.303 and $0.848 \mathrm{~kg} / \mathrm{t}$ ) at the second deoxidation were performed.

Figure 11 shows the changes of the $\mathrm{Al}$ and $\mathrm{Mg}$ contents in the molten steel: The Mg content decreases with decreasing additional amount of Al. Figure 12 shows the calculated changes in the amount of spinel: The amount of spinel decreases with decreasing amount of $\mathrm{Al}$ added after the second deoxidation; however, spinel forms under all the investigated conditions. From these results, it was concluded that the formation of spinel can be slightly suppressed by reducing the additional amount of $\mathrm{Al}$. 


\subsection{Effect of MgO Content in the Slag on Composition Change in the Inclusions}

The formation of $\mathrm{Mg}$ in molten steel is mostly caused by a reaction between the molten steel and slag phases. Therefore, the formation of spinel can be suppressed if the content of $\mathrm{MgO}$, which is the source of $\mathrm{Mg}$, in the slag is decreased. Thus, the composition change in the inclusions with varying initial $\mathrm{MgO}$ content in the slag (from 2.3 to 6.3 mass\%) was investigated.

Figure 13 shows the changes in the contents of $\mathrm{MgO}$ in
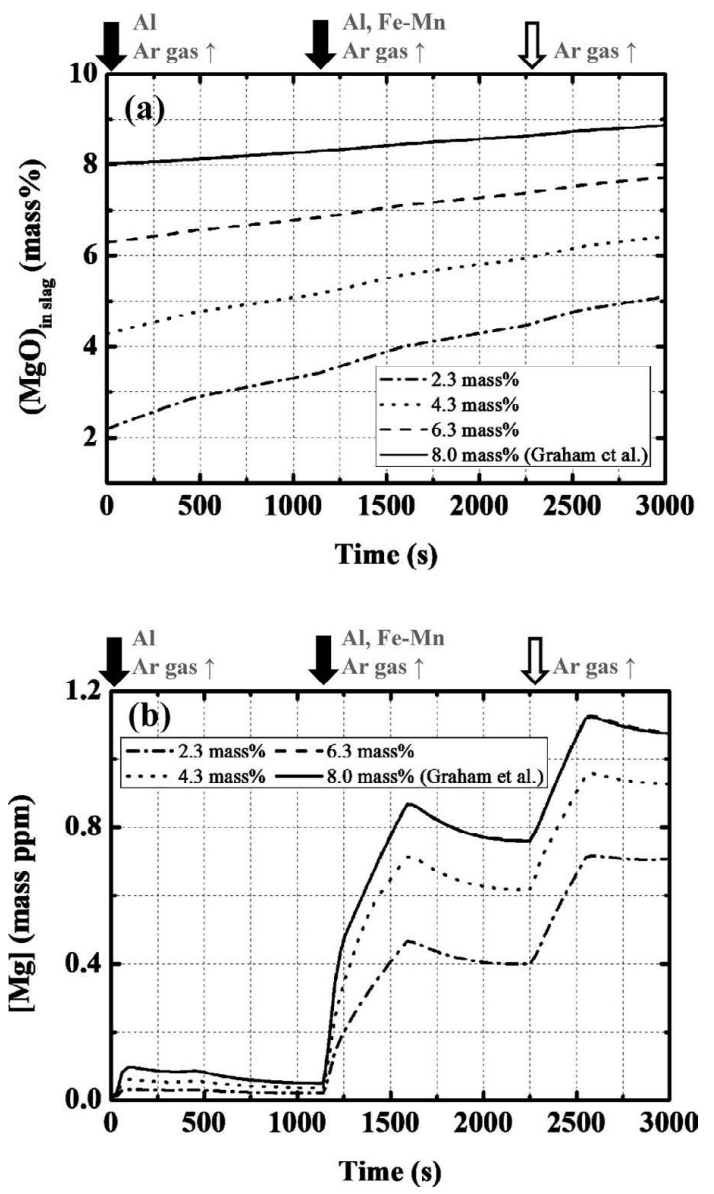

Fig. 13. Calculation results of the concentration of (a) $\mathrm{MgO}$ in the slag and (b) $\mathrm{Mg}$ in the molten steel with the change in the initial concentration of $\mathrm{MgO}$ in the slag.

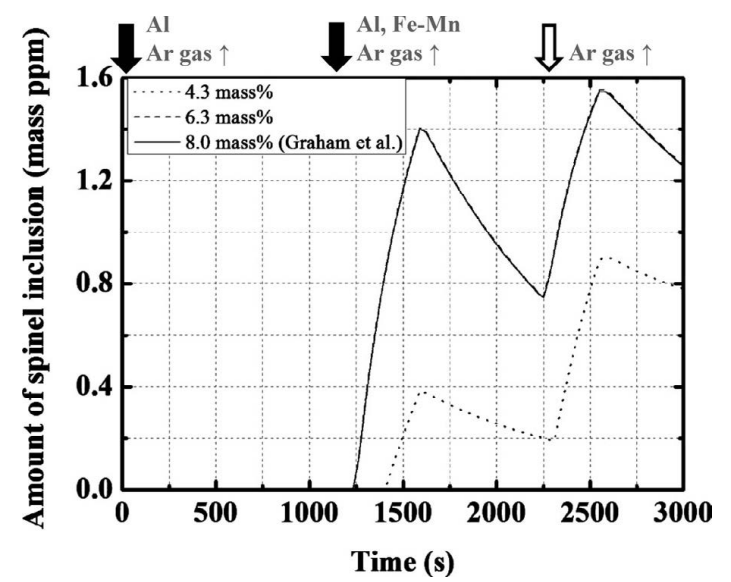

Fig. 14. Calculation results of the amount of spinel type inclusion with the change in the content of $\mathrm{MgO}$ in the slag. the slag and $\mathrm{Mg}$ in the molten steel. The content of $\mathrm{Mg}$ decreases with decreasing initial content of $\mathrm{MgO}$ in the slag. Figure 14 shows the calculated change in the amount of spinel: The amount of spinel decreases with decreasing content of $\mathrm{MgO}$ in the slag and does not form after the second deoxidation when the initial $\mathrm{MgO}$ content in the slag is lower than 2.3 mass \%. However, the dissolution of refractory containing $\mathrm{MgO}$ increases with decreasing initial content of $\mathrm{MgO}$ in the slag, as shown in Fig. 13. Therefore, with increasing initial content of $\mathrm{MgO}$ in the slag, spinel-type inclusion forms during the last stage of the treatment.

\subsection{Effect of Slag Basicity on Composition Change in the Inclusions}

Nishi et al. ${ }^{3)}$ and Okuyama et $a l .{ }^{4)}$ estimated the effect of slag basicity on the composition change in the inclusions using laboratory-scale experiments. According to their results, the content of $\mathrm{Mg}$ in molten steel decreased and the formation of spinel was suppressed as the basicity decreased. Here, the effect of slag basicity on the composition change in the inclusions is investigated. Table 2 shows the basicity values and the corresponding compositions of the slag. In this calculation, slag is assumed as a uniform liquid phase and the difference in fluidity is not considered.

The calculated changes in the Mg content in the molten steel are shown in Fig. 15. As the basicity decreases, the $\mathrm{Mg}$ content in the molten steel also decreases; this is because the activity of $\mathrm{MgO}$ decreases with decreasing slag basicity and the reduction of $\mathrm{MgO}$ is suppressed. The calculated changes in the amount of spinel are shown in Fig. 16. If the slag basicity is lower than 4.0, spinel does not form. Therefore,

Table 2. Calculation conditions in discussion about the slag basicity.

\begin{tabular}{cccccccccc} 
& & & & & & & & $($ mass\%) \\
\hline No. 1 & 8 & 32 & 19.1 & 38.2 & 0.8 & 1.9 & 0.01 & 2.0 \\
No. 2 & 8 & 32 & 11.5 & 45.9 & 0.8 & 1.9 & 0.01 & 4.0 \\
No. 3 & 8 & 32 & 8.2 & 49.2 & 0.8 & 1.9 & 0.01 & 6.0 \\
Graham et al. & 8 & 32 & 5.9 & 51.5 & 0.8 & 1.9 & 0.01 & 8.7 \\
\hline
\end{tabular}

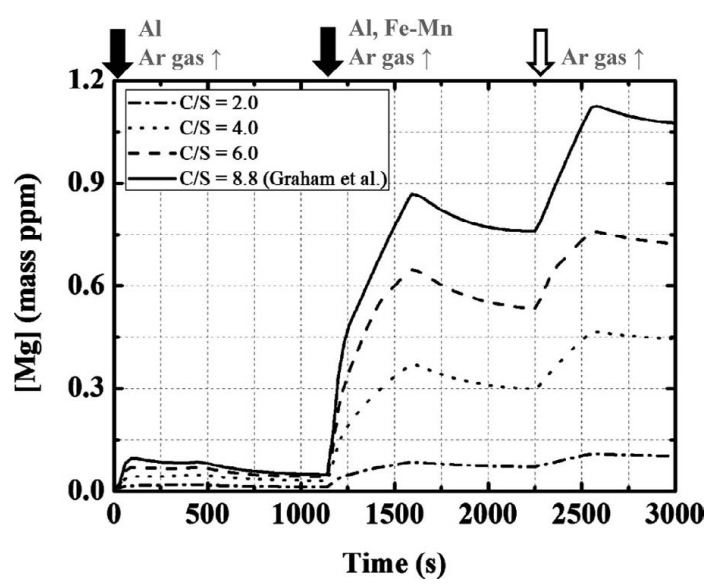

Fig. 15. Calculation results of the concentration of $\mathrm{Mg}$ in the metal with the change in the basicity of slag. 
optimization of slag basicity is effective for suppressing the formation of spinel.

\subsection{Thermodynamic Considerations}

Here, the calculated results are discussed from a thermodynamic perspective. To estimate the composition of the inclusions, a phase stability diagram for $\mathrm{MgO}, \mathrm{MgO} \cdot \mathrm{Al}_{2} \mathrm{O}_{3}$, and $\mathrm{Al}_{2} \mathrm{O}_{3}$ was used. The results obtained using the developed model were then compared with the phase stability diagram. Todoroki et al. ${ }^{5)}$ reported the phase stability diagram using the following calculations. The thermodynamic data used for the stability diagram are listed in Table 3 . These data are same with those used in the developed model.

The following reaction was considered to calculate the boundary between $\mathrm{MgO}$ and $\mathrm{MgO} \cdot \mathrm{Al}_{2} \mathrm{O}_{3}$ :

$$
4 \mathrm{MgO}+2 \underline{\mathrm{Al}}=\mathrm{MgO} \cdot \mathrm{Al}_{2} \mathrm{O}_{3}+3 \underline{\mathrm{Mg}}
$$

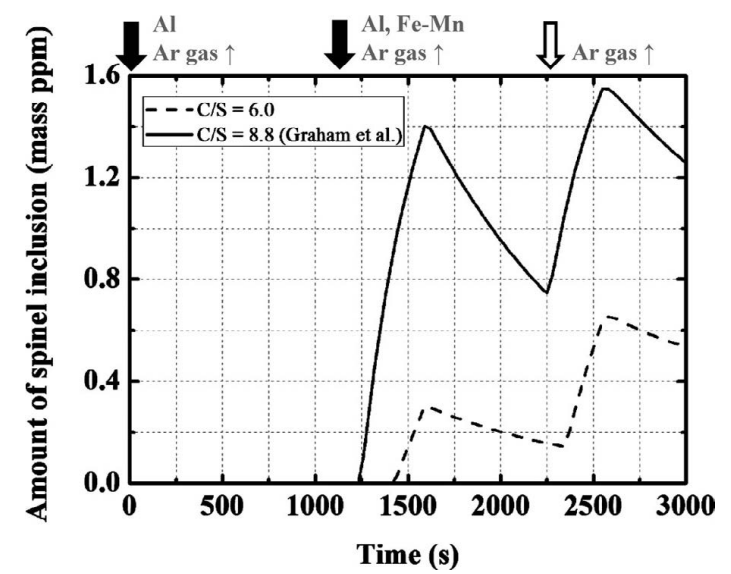

Fig. 16. Calculation results of the amount of spinel type inclusion with the change in the basicity of slag.
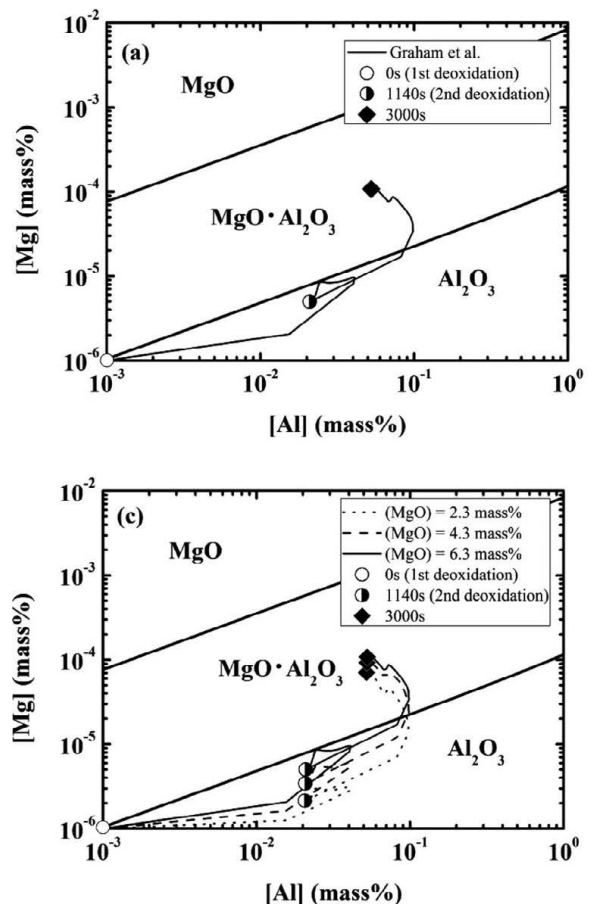

The corresponding equilibrium constant is given by Eqs. $(3)^{6-8)}$ and (4).

$\log K_{\text {eq.(2) }}=-23.64+35585 / \mathrm{T}$.

$$
K_{\text {eq. (2) }}=\frac{a_{\mathrm{MgO} \cdot \mathrm{Al}_{2} \mathrm{O}_{3}} \cdot a_{\mathrm{Mg}}^{3}}{a_{\mathrm{MgO}}^{4} \cdot a_{\mathrm{Al}}^{2}}=\frac{a_{\mathrm{MgO} \cdot \mathrm{Al}_{2} \mathrm{O}_{3}} \cdot f_{\mathrm{Mg}}^{3} \cdot[\text { mass } \% \mathrm{Mg}]^{3}}{a_{\mathrm{MgO}}^{4} \cdot f_{\mathrm{Al}}^{2} \cdot[\text { mass } \% \mathrm{Al}]^{2}}
$$

The following reaction was considered to calculate the boundary between $\mathrm{MgO} \cdot \mathrm{Al}_{2} \mathrm{O}_{3}$ and $\mathrm{Al}_{2} \mathrm{O}_{3}$ :

$$
3 \mathrm{MgO} \cdot \mathrm{Al}_{2} \mathrm{O}_{3}+2 \underline{\mathrm{Al}}=4 \mathrm{Al}_{2} \mathrm{O}_{3}+3 \underline{\mathrm{Mg}} \text {. }
$$

The corresponding equilibrium constant is given by Eqs. $(6)^{6-8)}$ and (7).

$$
\log K_{\text {eq.(5) }}=-26.92+27940 / \mathrm{T}
$$

Table 3. Equilibrium constants of reactions used in this study.

\begin{tabular}{|c|c|c|c|c|c|}
\hline \multirow{2}{*}{\multicolumn{2}{|c|}{$e_{i}^{j}$}} & \multicolumn{4}{|c|}{$J$} \\
\hline & & $\mathrm{Mn}$ & $\mathrm{Si}$ & $\mathrm{Mg}$ & $\mathrm{Al}$ \\
\hline \multirow{3}{*}{$i$} & $\mathrm{Mg}$ & - & $-0.088^{9)}$ & - & -0.017 \\
\hline & $\mathrm{Al}$ & -0.004 & 0.056 & $-0.13^{9)}$ & $80.5 / \mathrm{T}$ \\
\hline & $\mathrm{O}$ & -0.021 & -0.066 & $-300^{10,11)}$ & $1.9-5.750 \times 10^{3} / \mathrm{T}^{12)}$ \\
\hline
\end{tabular}

\begin{tabular}{ccc}
\hline & $\log \mathrm{K}$ & Ref. \\
\hline $\mathrm{Al}_{2} \mathrm{O}_{3}(\mathrm{~s})=2 \underline{\mathrm{Al}}+3 \underline{\mathrm{O}}$ & $11.62-45300 / \mathrm{T}$ & $6)$ \\
$\mathrm{MgO}(\mathrm{s})=\underline{\mathrm{Mg}}+\underline{\mathrm{O}}$ & $-4.28-4700 / \mathrm{T}$ & $7)$ \\
$\mathrm{MgO} \cdot \mathrm{Al}_{2} \mathrm{O}_{3}(\mathrm{~s})=\mathrm{Al}_{2} \mathrm{O}_{3}(\mathrm{~s})+\mathrm{MgO}(\mathrm{s})$ & $-0.604-1080 / \mathrm{T}$ & $8)$
\end{tabular}

Table 4. First order interaction coefficients used in this study (All data without notation are from reference No. 8).
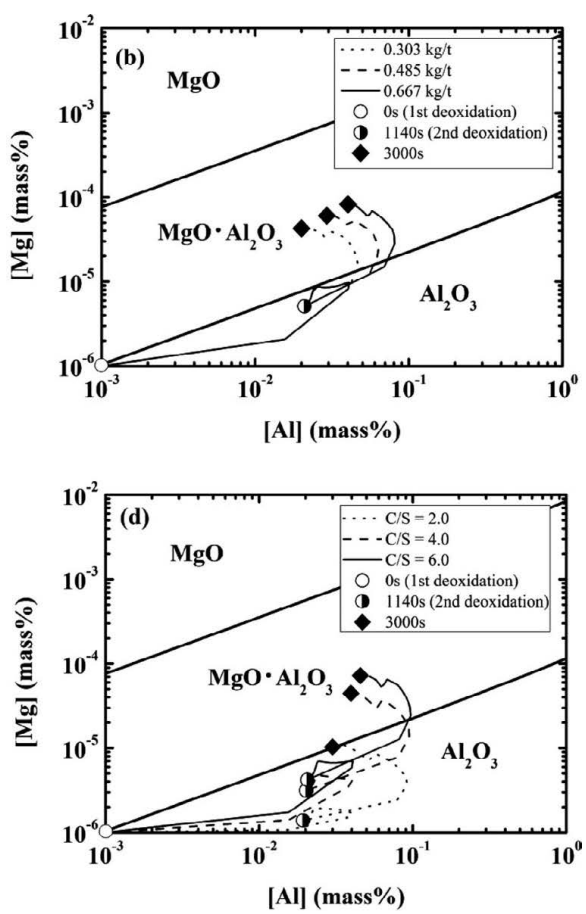

Fig. 17. Phase stability diagram for $\mathrm{MgO}, \mathrm{MgO} \cdot \mathrm{Al}_{2} \mathrm{O}_{3}$ and $\mathrm{Al}_{2} \mathrm{O}_{3}$-type inclusions along with the composition change in $\mathrm{Mg}$ and $\mathrm{Al}$ under every condition ((a) Graham et al., (b) Change in additional amount of $\mathrm{Al}$, (c) Change in $\mathrm{MgO}$ content in slag and (d) Change in the slag basicity). 


$$
K_{\text {eq. (5) }}=\frac{a_{\mathrm{Al}_{2} \mathrm{O}_{3}}^{4} \cdot a_{\mathrm{Mg}}^{3}}{a_{\mathrm{MgO} \cdot \mathrm{Al}_{2} \mathrm{O}_{3}}^{3} \cdot a_{\mathrm{Al}}^{2}}=\frac{a_{\mathrm{Al}_{2} \mathrm{O}_{3}}^{4} \cdot f_{\mathrm{Mg}}^{3} \cdot[\text { mass } \% \mathrm{Mg}]^{3}}{a_{\mathrm{MgO} \cdot \mathrm{Al}_{2} \mathrm{O}_{3}}^{3} \cdot f_{\mathrm{Al}}^{2} \cdot[\text { mass } \% \mathrm{Al}]^{2}}
$$

$$
\begin{aligned}
\log f_{\mathrm{Al}} & =\Sigma e_{\mathrm{Al}}^{j} \cdot[\operatorname{mass} \% j] \\
\log f_{\mathrm{Mg}} & =\Sigma e_{\mathrm{Mg}}^{j} \cdot[\operatorname{mass} \% j]
\end{aligned}
$$

As shown in Table 4, ${ }^{7,9-12)} e_{i}^{j}$ is the first-order interaction coefficient. The boundaries were calculated by combining Eqs. (3), (4), and (6)-(9).

The calculated phase stability diagrams are shown in Fig. 17 along with the calculated results discussed in the previous sections.

Figure 17(a) shows the calculation results under the conditions used in the study reported by Graham et al. It can be found that the composition moves from an alumina-stable region to a spinel-stable region during treatment. Figures 17(b) and 17(c) show the calculation results when the additional amount of $\mathrm{Al}$ or the initial content of $\mathrm{MgO}$ in the slag are changed, respectively. In every case, the compositions move from the alumina-stable region to the spinel-stable region. This is a reason why spinel formation is not suppressed by either decreasing the additional amount of $\mathrm{Al}$ or decreasing the initial content of $\mathrm{MgO}$ in the slag. Figure 17 (d) shows the calculated results when the slag basicity is changed. At the basicity of 4.0 and 6.0 , the composition moves from the alumina-stable region to the spinel-stable region. In contrast, the calculated compositions remain in the alumina-stable region at the basicity of 2.0.

These comparisons indicate that the calculated changes in the inclusions are in good agreement with those predicted by the phase stability diagram.

To reduce the formation of spinel-type inclusions, optimization of the additional amount of $\mathrm{Al}$, the initial content of $\mathrm{MgO}$ in the slag, and slag basicity is effective in addition to the $\mathrm{Ca}$ treatment.

\section{Conclusions}

A kinetic model to simulate the reactions in a ladle furnace was developed. In this paper, the influence of some parameters in this model on the calculation results was investigated. The amount of inclusions is affected by the ratio of entrapment of slag in the molten steel $(\alpha)$ and the ratio of floatation of the inclusion in the slag $(\beta)$. The average concentration of inclusions is affected by the ratios of entrapment of slag in the molten steel $(\alpha)$ and agglomeration of the inclusions $(\gamma)$. However, the influence of the ratio of the bulk zone in the molten steel and slag phase was insignificant.

Then, the method to suppress the formation of $\mathrm{MgO} \cdot \mathrm{Al}_{2} \mathrm{O}_{3}$ spinel-type inclusion was discussed using the optimized parameters. The calculated results show that the formation of $\mathrm{MgO} \cdot \mathrm{Al}_{2} \mathrm{O}_{3}$ spinel-type inclusion can be suppressed by optimizing the additional amount of $\mathrm{Al}$, initial content of $\mathrm{MgO}$ in the slag, and slag basicity in addition to the $\mathrm{Ca}$ treatment. The changes in the inclusions calculated using the kinetic model are in good agreement with those predicted by the phase stability diagram. Therefore, the developed model is useful for optimizing the operation of a ladle furnace.

\section{Acknowledgments}

The authors appreciate the financial support of the Research Grant of the $19^{\text {th }}$ Committee of Steelmaking, the Japan Society for the Promotion of Science, and the ISIJ Research Promotion Grant of Iron and Steel Institute of Japan.

\section{REFERENCES}

1) A. Harada, N. Maruoka, H. Shibata and S. Kimtaura: ISIJ Int., to be published.

2) K. J. Graham and G. A. Irons: Proc. of Int. Symp. Highly Innovative Novel Operations "Future Steelmaking Metallurgy", ISIJ, Tokyo, (2010).

3) T. Nishi and K. Shinme: Tetsu-to-Hagané, 84 (1998), No. 12, 1.

4) G. Okuyama, K. Yamaguchi, S. Takeuchi and K. Sorimachi: ISIJ Int., 40 (2000), No. 2, 121.

5) H. Todoroki and K. Mizuno: ISIJ Int., 44 (2002), No. 8, 1350.

6) Recommended Values of Equilibrium Constants for the Reactions in Steelmaking, Japan Society for the Promotion of Science, 19th Committee, Tokyo, (1984), 255.

7) H. Itoh, M. Hino and S. Ban-ya: Tetsu-to-Hagané, 83 (1997), 623.

8) H. R. Rein and J. Chipman: Trans. Met. Soc. AIME, 233 (1965), 415.

9) Q. Han: Proc. of 6th Int. Iron Steel Cong., Vol. 1, ISIJ, Tokyo, (1990), 166.

10) H. Ohta and H. Suito: ISIJ Int., 43 (2003), 1293.

11) H. Ohta and H. Suito: ISIJ Int., 43 (2003), 1301.

12) H. Itoh, M. Hino and S. Ban-ya: Tetsu-to-Hagané, 83 (1997), 773. 